\title{
Mesoamérica o el Proyecto Mesoamérica: la historia COMO PRETEXTO
}

\author{
Jorge Luis Capdepont Ballina
}

Resumen: Este trabajo se centra en el análisis del contexto histórico en el cual se inserta el Proyecto Mesoamérica, poniendo en duda la versión oficial de que es una propuesta que pretende abatir los índices de rezago económico y social del sur-sureste de México y Centroamérica, cuando todo parece indicar que es uno más de los intentos por aprovechar la ubicación estratégica de la región y sus valiosos recursos naturales - forestales, minerales e hídricosen beneficio de las grandes potencias mundiales, sobre todo Estados Unidos. Los resultados obtenidos hasta el momento desde la puesta en marcha del Plan Puebla-Panamá, ahora Proyecto Mesoamérica, nos muestran que ha mejorado la infraestructura de comunicaciones y transportes en la zona, pero continúa existiendo una alta marginación social y económica de los habitantes; mientras que las nuevas estrategias del convenio apuntan hacia un claro aprovechamiento y explotación de los recursos naturales, más que a promover la industrialización con tecnología de punta y la propia conservación del medio ambiente.

Palabras clave: Mesoamérica, Plan Puebla-Panamá, Proyecto Mesoamérica, justificación histórica, aprovechamiento de recursos naturales.

Nota aclaratoria: por error de impresión en nuestro número anterior, este artículo salió incompleto; extendemos una disculpa al autor y a nuestros lectores.

Enviado a dictamen: 25 de enero de 2010

Aprobación: 15 de abril de 2010

Revisiones: 1

Jorge Luis Capdepont-Ballina, maestro y doctor en Historia por El Colegio de Michoacán, A. C., investigador asociado de El Colegio de la Frontera Sur Unidad Villahermosa. Temas de especialidad: investigación histórica de Tabasco en los siglos XIX y XX, particularmente en temas de explotación de recursos forestales, economía, historiografía, estudios demográficos. Correoselectrónicos:jlcapdepont@hotmail.com,jlcapdepont@yahoo.com.mx.
Abstract: This work focuses on the analysis of the historical context related to the Proyecto Mesoamérica, questioning the official version that tries to bring down the economical rates indexes and social backwardness of the south-south-east of Mexico and Central America, when everything seems to indicate that it is one more of the attempts for taking advantage of the strategic location of the region and its valuable natural resources (forest, mineral and water), in benefit of the big world powers, especially The United States. The results obtained till now from the putting in march of the Plan Puebla-Panamá, now Proyecto Mesoamérica, indicate that communications and transport infrastructure have improved in the area, but continues existing a high social and economic marginalization of the people; whereas the new strategies of the agreement appear towards a clear utilization and exploitation of the natural resources, more than to promoting the industrialization with technology of top and the own conservation of the environment.

Keywords: Mesoamerica, Plan Puebla-Panama, Proyecto Mesoamerica, historical justification, use of natural resources.

\section{Palabras preliminares}

$\mathrm{E}$ ste trabajo es un análisis en perspectiva histórica sobre el espacio que se ha denominado "Mesoamérica"; tiene el objetivo de exponer cómo se utiliza este concepto para justificar un plan económico que toma la Historia como el elemento que otorga legitimidad. Por lo tanto, el punto central de la discusión no será el Proyecto Mesoamérica, PM, por 
sí mismo, sino todo el contexto histórico en que se ve envuelto. Se puede decir que Proyecto Mesoamérica es más una iniciativa de las grandes potencias económicas a escala mundial, principalmente Estados Unidos, que una propuesta surgida desde los propios países centroamericanos y México.

El trabajo está estructurado en dos partes: en la primera comenzaremos por precisar qué se entiende por "Mesoamérica" y cómo surge dicho concepto histórico, luego señalaremos los principales intentos de algunas potencias europeas y Estados Unidos para apropiarse de este espacio; en la segunda parte se expone PM como uno más de estos propósitos. Para sustentar nuestra idea, revisamos parte de la bibliografía producida sobre el tema y la documentación oficial del convenio.

Lo que se intenta entonces es poner al descubierto el doble discurso que encierra el documento oficial de PM promovido por estos países. No se trata de oponerse a este proyecto por el simple hecho de cuestionar y denostar a los gobiernos centroamericanos y mexicano, sino analizar PM como una iniciativa más para aprovechar los recursos naturales: biodiversidad, agua, petróleo y otros minerales de la zona, que para beneficio de la sociedad que la habita.

\section{Un lugar llamado "Mesoamérica”}

Desde el momento en que se descubrió la importancia de este pequeño espacio del continente americano que hoy es el sur sureste de México y Centroamérica, ha sido objeto de innumerables disputas entre las potencias europeas y Estados Unidos para obtener su control absoluto. Su ubicación es estratégica, ya que permite cortar camino en la comunicación de los océanos Atlántico y Pacífico por vía marítima, esto genera reducción de gastos en transporte y ahorro de tiempo. Además, es una de las zonas más ricas en biodiversidad del continente americano - y el planeta- junto con la Amazonia y África; alberga una gran veta turística que ha sido relativamente explotada sobre todo en la segunda mitad del siglo XX, ya que en ella se encuentran innumerables zonas arqueológicas y majestuosos paisajes naturales; pero más que esto, en ella existe una de las más grandes reservas de petróleo que hay en el mundo y no debe olvidarse, claro, que es la zona que tiene más recursos hídricos - agua dulce- en el continente americano.

Pese a todas estas "virtudes", en la actualidad es una de las zonas más atrasadas económicamente de América, y en el ámbito mundial apenas supera a algunos países africanos y de medio oriente. A esto le añadimos que los regímenes políticos en vigor son demasiado débiles e inestables — salvo México y Costa Rica, que gozan de relativa estabilidad con democracias en proceso de consolidación-, además de enfrentar serios problemas de salud, educación, servicios, seguridad pública varios de ellos enfrentan a grupos guerrilleros y de narcotraficantes que amenazan la paz interna- y con frecuencia son amenazados por fenómenos naturales. A lo largo de cinco siglos, Mesoamérica ha desempeñado el papel de "manzana de la discordia", que en vez de ayudarle a superar sus problemas ha provocado un estancamiento económico severo y una marginación social lamentable. Hoy enfrenta un ataque más, la pregunta es icuáles serán las consecuencias? Antes de analizar el problema que le abruma en la actualidad, conviene recordar algunos detalles de su odisea a lo largo de los últimos quinientos años.

Hacia 1492, cuando los españoles tuvieron contacto accidental con estas "nuevas" tierras, pensaron que habían encontrado una ruta más corta para llegar a las "Indias orientales", Asia. La confusión se originó porque algunas personas tenían la idea de que el mundo era muy pequeño y redondo y era posible, como pensaba Cristóbal Colón, darle la vuelta en poco tiempo si se continuaba navegando hacia el mismo punto en dirección a occidente. Al tener contacto con los habitantes de estas tierras, los "extranjeros" no tardaron en darse cuenta de que habían llegado a un lugar diferente al que ellos pensaban al principio. 
Años después, los europeos iniciaron la exploración de este "Nuevo mundo", con la idea de encontrar nuevos mercados para desplazar sus mercancías y, sobre todo, en búsqueda de riquezas, ya fueran minerales —oro y plata - o naturales. Grande fue su sorpresa al "descubrir" a lo largo y ancho de estas tierras grupos humanos que tenían una compleja organización social, política y militar. El gran dilema de los conquistadores colonizadores fue icómo llamar a estas personas?, ¿quiénes eran?, ¿cómo habían llegado aquí?, ipor qué no había referencias de ellas en las sagradas escrituras? Fue un largo proceso para construir una identidad para esta gente; este asunto no es objeto del presente trabajo, por lo que solo se señala como referencia. Para no hacer más larga la digresión, solamente diremos que estas tierras fueron llamadas originalmente "Indias", luego se les añadió "occidentales" para diferenciarlas de las "Indias orientales", cuyo gentilicio era "indios"; posteriormente recibieron el nombre de América y sus habitantes "americanos".

Luego de los múltiples movimientos de emancipación, varias de estas antiguas colonias españolas se transformaron en Estados nación, con un nombre propio, y la gran masa terrestre quedó identificada como América. El establecimiento de las delimitaciones político administrativas fue arbitrario, tanto como lo había sido el proceso de conquista y colonización por parte de los europeos, ya que se ignoró la historia individual de los grupos, así como sus costumbres, tradiciones, organización política y social, religión, etc. Ese es el caso de este espacio medio del continente americano. Desde entonces, ha habido un gran interés por parte de destacadas personalidades, desde cronistas, eclesiásticos, aventureros, pasando por poetas y llegando a arqueólogos, antropólogos e historiadores, por conocer más sobre cada uno de estos grupos humanos. Así, se ha estudiado y dado nombre a cada uno de ellos: olmecas, huastecos, zapotecos, totonacas, toltecas, purépechas, aztecas, mayas, entre muchos otros. No fue sino hasta 1943 cuando el destacado etnólogo y lingüista alemán, Paul Kirchhoff, llamó y definió a casi todo este segmento del continente —ver mapa 1-: "Mesoamérica" (Kirchhoff, 2009: 1-18; Jiménez, 1979: 21).

Este término - hoy un concepto- hacía una clara distinción entre la parte sudamericana con una marcada tradición "inca"-, y poco más arriba de la mitad de México hacia el norte del continente —conocido como "Aridoamérica", por las características geográficas de la zona-. El argumento de Kirchhoff se sustentaba en varios elementos: primero, un alto grado de "civilización", caracterizado por una compleja organización política y social, una red económica bastante desarrollada, además de compartir algunos rasgos y elementos culturales como alimentación, educación, lengua, vestido y otros; segundo, un área geográfica bastante homogénea, caracterizada por numerosos ríos, abundante vegetación y fauna, lo que según Kirchhoff favoreció un alto grado de "civilización", ya que el medio les aportaba mucho más de lo que necesitaban para vivir y les permitía acumular e intercambiar sus bienes; tercero, una tradición arquitectónica y tecnológica más o menos común, caracterizada por majestuosas construcciones - centros ceremoniales y político militares - a lo largo y ancho de este espacio; y cuarto, cultos religiosos bien definidos pero con ciertas afinidades, ya que tenían algunos dioses y prácticas rituales comunes (Kirchhoff, 2009: 4-12; Jiménez, 1979: 11-25).

Los estudios sobre este espacio se han multiplicado a lo largo de las últimas décadas y han arrojado importantes conocimientos sobre estos pueblos. No es objeto de este trabajo darlos a conocer, ya que en todo caso es más recomendable ir directamente a las obras de los más destacados arqueólogos, antropólogos e historiadores que se han encargado del asunto. Nuestro propósito es hacer referencia al origen del término "Mesoamérica", que será importante para la estructura de este trabajo. 
Laimportancia de este espacio fue reconocida por los españoles a principios del siglo XVI, cuando concibieron la idea de que habían encontrado un continente hasta entonces desconocido; de tal manera que se inició una nueva etapa en la historia de la humanidad, el "mundo" dejó de ser Europa, África y Asia, ya que se agregó este "Nuevo Mundo" que lo complementó. A pesar de el hallazgo de los europeos, el objetivo no fue el conocimiento de nuevos pueblos, sino la búsqueda de rutas más cortas para desplazar las mercancías hacia las Indias orientales - Asia- y aumentar las riquezas de la Corona española. ${ }^{2}$ Comenzó así una lucha por apropiarse de las nuevas rutas y mercados, y por ende de los nuevos territorios como puntos estratégicos para lograr dicho propósito (García Fuentes, 1980; Rodríguez, 2000). El buen posicionamiento en el Caribe ${ }^{3}$ garantizaba a España el desplazamiento de mercancías y riquezas hacia Filipinas y otros lugares de Asia - la ruta España-La Habana-Veracruz-Ciudad de MéxicoAcapulco-Manila-, así como también la comunicación con Perú y las minas del Potosí - España-La HabanaPortobelo-El Callao.

Las noticias sobre un Nuevo Mundo se difundieron en Europa y, claro, las demás potencias no permitirían —o al menos tratarían de evitarlo- que España se quedara con todo. Pronto llegaron los franceses a las aguas americanas, le siguieron los ingleses y holandeses, más tarde los portugueses, daneses y otros. Pero la mayoría de los que cruzaron "el charco" no fueron gente común, sino los temidos "perros del mar": ilos piratas! Se inició en el Caribe una lucha frontal de los españoles contra los usurpadores para defender sus posiciones estratégicas: los puertos y ciudades ubicados en las costas del Golfo de México, el Mar Caribe y también el Océano Pacífico. Durante los tres siglos de la colonización española en América, e incluso hasta mediados del siglo XIX, los piratas asolaron la zona. ${ }^{4}$

El objetivo de las incursiones piratas en el siglo XVI era apoderarse de las mercancías y riquezas transportadas por las flotas españolas, llevarlas a sus países o venderlas al mejor postor; en el siglo XVII la finalidad fue posicionarse en el Caribe, tomando algunas ciudades y puertos para establecer sus bases de operaciones en América, y por qué no colonizarlos. Durante el siglo XVI, cuando se detectó la presencia de piratas franceses, y más tarde ingleses en la zona del Caribe, las autoridades indianas consideraron necesario crear planes para proteger las flotas y galeones, las costas de la Nueva España y combatir el contrabando. Las medidas tomadas podemos decir que fueron dos: la primera, crear un sistema defensivo terrestre - fijo-, que protegería las costas cercanas a las ciudades y puertos, formado por fortalezas - reales, castillos, fuertes, ciudadelas, murallas, baterías, fortines, etcétera-; y la segunda, organizar un sistema defensivo naval —móvil-, que vigilaría y defendería las rutas comerciales, así como las costas, integrado por barcos de guerra o las propias embarcaciones que transportaban las mercancías (Calderón, 1996; Pérez-Mallaína; Torres, 1987; Rahn, 1991).

Las autoridades coloniales -españolas y americanas - estuvieron siempre dispuestas a enfrentar a los invasores piratas para proteger sus dominios, sabiendo de antemano que el control del Caribe garantizaba el tránsito de la Carrera de Indias y el aprovechamiento de las riquezas de América. Las otras potencias europeas como Inglaterra, Francia y Holanda, lo sabían, por múltiples medios como la piratería intentaron posicionarse en la zona para participar de los bienes que proporcionaba el Nuevo Mundo.

Al final, los ingleses tomaron una plaza - Jamaica en 1655- y la convirtieron en la base principal de sus operaciones, venta de esclavos y manufacturas y tráfico del palo de tinte que extraían de manera ilegal en las costas de Campeche y Yucatán; los franceses ocuparon una parte de La Española entre 1650-1660, la convirtieron en Santo Domingo — hoy Haití - difundiendo el cultivo del café; mientras que los holandeses se apoderaron de una isla - Curaçao en 1634-, de donde partían para la 
comercialización del tabaco. España se quedó con el resto y se ocupó del comercio del cacao, azúcar, maderas preciosas, palo de tinte, cochinilla, oro y plata, que en varias ocasiones cayeron en manos de los piratas. ${ }^{5} \mathrm{El}$ dominio en el Caribe se diversificó, España cedió parte de su poderío sobre él, o al menos se conformó con tener huéspedes o visitantes permanentes incómodos, que se llevaban parte de su riqueza, ya sea comerciando con sus colonias o robándolas.

El papel desempeñado por Centroamérica a través del tiempo ha sido el de zona de disputa territorial entre las grandes potencias europeas - se sumó a fines del siglo XIX, Estados Unidos-, con el objetivo de explotar sus materias primas y después como vía más adecuada para facilitar el tránsito mercantil entre Europa y Asia (véase sobre el tema Lowell, 1990; MacLeod, 1980). Cabe mencionar que desde que se tomó conciencia de que estas tierras constituían un nuevo continente, también se afirmó la idea de que el planeta era redondo, por tanto, si se continuaba la ruta hacia occidente se daría la vuelta al mundo y en algún momento se llegaría a Asia; de tal manera que desde ese momento se inició la búsqueda del lugar idóneo — más angosto - para atravesar el continente (Pérez, 1999).

Desde la época colonial se pretendía encontrar una vía que comunicara los océanos Pacífico y Atlántico, pero se fue perdiendo el interés por diversas circunstancias administrativas y escasez de recursos; la idea recobró impulso a principios del siglo XIX cuando Alexander von Humboldt destacó las ventajas que significaba construir un canal en Centroamérica, porque era la franja terrestre más angosta del continente americano, y se inclinaba más por Nicaragua (Rajchenberg y Héau-Lambert, 2003; Beas, 2003; García A., 2003; Bonilla, 2003). Se hicieron varios proyectos con el objetivo de encontrar el sitio más adecuado para atravesar de un océano a otro, entre los que destacan: el Istmo de Tehuantepec; en Honduras se trató de unir el Puerto Caballos y el Golfo de Fonseca con una vía ferroviaria; en Nicaragua se descubrió que el lago de Nicaragua desagua en el Mar Caribe a través del río San Juan, y del océano Pacífico se podía trazar un camino corto de 18 kilómetros al lago; finalmente se encontró que la ruta más propicia se encontraba en Panamá, que había sido utilizada por los españoles desde 1520 (García, 1945).

El tránsito de Panamá a Cruces se hacía en mula, de este punto se continuaba por el río Chagres hasta la Fortaleza y de ahí a Portobelo; esta ruta fue la más utilizada en el período colonial, sin embargo, a partir de 1739 enfrentó una paulatina decadencia. No fue sino hacia mediados del siglo XIX cuando se puso en marcha un ferrocarril que facilitó el recorrido de un extremo al otro (Pérez, 1999), y para finales de este siglo se comenzó a construir un gran canal, primero con capital francés y posteriormente estadounidense (Rosa, 1976). Cabe señalar que los encargados originales del proyecto se encontraron con muchas dificultades técnicas y financieras, que los obligaron a negociar con el gobierno de Estados Unidos la cesión de los derechos de construcción de la obra mediante el Tratado Hay-Bunau-Varilla en 1903; el asunto terminó con la separación de Panamá respecto de Colombia, auspiciada por los estadounidenses para tener un mayor control del canal.

Con la irrupción de Estados Unidos en la zona la vida de estos países cambió drásticamente, ya que se dejó sentir la autoridad política, económica y militar de este vecino incómodo. Con el argumento de ayudar a los panameños a administrar el canal, los estadounidenses ejercieron arbitrariamente su poder en la zona, instalaron varias bases militares supuestamente para proteger el canal, aunque en realidad fuera para mantener "pacificada" el área, en donde se gestaban varios movimientos de liberación nacional, y en la segunda mitad del siglo XX para evitar brotes de "comunismo" en la masa continental americana. ${ }^{6}$ Los que sufrieron esta intervención político militar no fueron solamente los países centroamericanos y antillanos sino también los sudamericanos. La influencia de Estados Unidos en la región se hizo 
más evidente en la segunda mitad del siglo XX. El papel jugado por los estadounidenses incluía la intervención en asuntos internos de estos países, tales como el establecimiento - y reconocimiento- de los gobiernos, políticas económicas, seguridad nacional, entre otros; la manera de llevar a cabo sus planes expansionistas fue mediante la presión económica, es decir, el condicionamiento de préstamos financieros a los gobiernos a cambio de numerosas concesiones como las señaladas. México no fue ajeno a esta situación (Aguirre, 2001: 51-54).

El interés de Estados Unidos en la zona resulta mera cuestión unilateral. A mediados del siglo XIX, más que búsqueda de mercados era de materias primas. A principios del siglo XX fue para extender su poder político militar en todo el continente y el mundo, y en la segunda mitad de este mismo siglo querían defender su área de influencia frente a la amenaza que representaba el comunismo ruso. En la actualidad, el objetivo es salvaguardar su zona de abasto de materias primas petróleo y otros recursos naturales-. En este recorrido, fugaz por el tiempo, hemos visto la tensión bajo la cual ha vivido este espacio del continente americano, jugando el papel de "manzana de la discordia", porque tanto las potencias europeas como Estados Unidos han comprendido su importancia.

Recordando lo mencionado en líneas anteriores, esta zona tiene características geográficas, rasgos culturales, espacios económicos e historia comunes. Desde la época colonial, los españoles organizaron su administración tomando en cuenta la que existía hasta antes de su llegada y lograron establecer dos zonas con delimitaciones claras: por un lado la audiencia de Nueva España además de Nueva Galicia, Yucatán y las Provincias Internas; y por el otro, la audiencia de Guatemala — que incluía casi toda Centroamérica a excepción de Panamá y el territorio que ocuparon los ingleses, Belice.

Para el caso de México - que comprende aproximadamente las antiguas audiencias de Nueva
España, Nueva Galicia, Yucatán y las Provincias Internas-, durante la época colonial la zona sur sureste siempre fue marginada, ya que en el centro y occidente se concentraron las sedes político administrativas y se trazaron rutas mercantiles hacia el norte relacionadas con la extracción de minerales - plata, principalmente-, de modo que la atención se centró en dos direcciones: centro-occidente-norte y centro-norte (Romero, 1999; Ibarra, 1999; Silva, 1999). En el sur, que no tenía riquezas minerales, no hubo interés sino para obtener recursos forestales y productos agropecuarios, y debido a la riqueza de las tierras no se invertía en mejoramiento material y mucho menos tecnológico, es decir, su papel era el de abastecedor de materias primas (Tudela, 1989: 34-41; Ruiz, 1994: 94-98, 2001: 90-91).

Durante el siglo XIX, después de la independencia, la situación del sur sureste continuó siendo similar, fue hacia finales de este siglo y principios del siguiente cuando se trató de unir con el resto de la joven nación a través de vías ferroviarias (Kuntz, 1999; Torruco, 1994: 155-164). El sistema económico que predominó fue el de las haciendas, que satisfacían las necesidades del mercado agrícola; mientras que en el norte, por una mejor infraestructura, mayor capital y su cercanía a Estados Unidos en plena expansión, fue posible crear industrias y redes mercantiles de mayor importancia y por ende mejores condiciones socioeconómicas de vida.

Hasta mediados del siglo XX se construyó una carretera - la carretera del Golfo- con una serie de ramificaciones que unía las principales ciudades de la zona con el centro y norte del país; siendo esta la primera vez que había una comunicación más eficiente por vía terrestre. En la segunda mitad de este mismo siglo se descubrieron importantes yacimientos petrolíferos en la región, dándose a partir de este momento un bum económico en la misma. Se erigió una gran infraestructura para facilitar la comunicación y transporte en la zona, sobre todo a las áreas de explotación petrolera. Asimismo, hubo movimientos poblacionales, ya que muchos trabajadores de diversas 
partes del país se trasladaron a estos lugares con sus familias, y se crearon programas de vivienda, educación, salud y otros servicios para satisfacer las necesidades básicas de los habitantes de las casi espontáneas ciudades (Tudela, 1989: 237-288; Capdepont, 2009: 40-41, 56-60)

Es de resaltar que si bien existe una infraestructura importante que permite la integración del área sur sureste de México, la economía ha girado en las últimas décadas en torno al petróleo y no se ha generado otro tipo de industria ni se han creado programas de subsidio para mejorar el sector primario. Por tanto, la pobreza de la región sigue siendo evidente en muchos lugares, ya que se continúan explotando sus riquezas, pero no se le ha retribuido los beneficios de la importante derrama económica que genera el petróleo -y derivados-, al contrario, los costos ecológicos y la marginación social son altos (Villafuerte, 2001: 13-26, 75-133; Tudela, 1989: 353-445; Capdepont, 2009: 46-50).

Por su parte, casi toda Centroamérica se unió en la época colonial bajo una unidad administrativa - la audiencia de Guatemala - y a lograr su independencia se fraccionó en Estados nación con un origen común: Guatemala, Honduras, Nicaragua, El Salvador, Costa Rica. El caso de Belice fue el de un protectorado inglés hasta 1981 que obtuvo su emancipación, pese al descontento de Guatemala que reclamaba dicho territorio desde finales del siglo XIX. Panamá administrativamente pertenecía al virreinato de Nueva Granada durante el período colonial, después de conseguir su independencia se adhirió a Colombia en 1822, y a principios del siglo XX se separó de esta y quedó bajo la tutela político económica de Estados Unidos hasta finales de la centuria comentada, cuando el gobierno panameño se hizo cargo absoluto del canal.

Desde los inicios de la época colonial hasta mediados del siglo XVII, la economía de Centroamérica se centró en dos polos: Panamá-Portobelo-Cartagena y Santiago de Guatemala — capital de la audiencia y sede de la Capitanía general一. Ya en el siglo XVII, se involucraron en el comercio de la zona los piratas y contrabandistas, principalmente ingleses, quienes se habían posesionado de Jamaica, y posteriormente de una franja de tierra continental, entre los límites de Guatemala y la península de Yucatán, hoy Belice. La economía de la zona era esencialmente agrícola y, salvo raras ocasiones, fue de nivel secundario (Lowell, 1990; MacLeod, 1980; Fonseca, 1992).

En el siglo XIX, después de los procesos de independencia, se hicieron varios proyectos para unificar nuevamente la zona centroamericana; por ejemplo, se intentó conformar la Federación Centroamericana, pero los intentos fracasaron debido a las diferencias políticas internas de cada una de las regiones que la conformaban, y por supuesto a la intervención de México, Inglaterra y sobre todo Estados Unidos, por proteger sus intereses económicos y políticos. Pese a ello, las negociaciones entre las diferentes naciones dio como resultado la estructuración de un Mercado Común Centroamericano en 1960, el primero en su tipo en Latinoamérica y el Caribe (Pérez, 1999). Este espacio no cuenta con los recursos petrolíferos como los que tiene el sur sureste de México, su economía gira alrededor de la producción agrícola y el desarrollo de las industrias es precario. Tanto Centroamérica como el sur sureste de México tienen condiciones de marginación social y económica similares (Compendio, 2001; Cedeño, 2002: 13-15; Bartra, 2001: 24-30 y 58-62).

Después de la Segunda Guerra Mundial, la situación económica de los países del mundo quedó claramente diferenciada. Se conformaron dos grandes bloques políticos: capitalismo —occidente- y socialismo -oriente- Asimismo, en medio de estos dos polos se caracterizó uno cuya economía no tenía los niveles de la mayor parte de estos, pese a que simpatizaban o con el capitalismo o el socialismo, despectivamente fue denominado "Tercer Mundo" por las deplorables condiciones de sus sistemas políticos, la pobreza y marginación de sus habitantes y los graves problemas de sus endebles economías. 
Al conformarse la Organización de las Naciones Unidas (ONU) se buscaron políticas para "ayudar" a estos países pobres, e incluso para explicar el origen y causa de su miseria y crear programas ajustados a sus necesidades. Es así como surge, para el caso de Latinoamérica, la Comisión Económica para América Latina (CEPAL), cuya misión era analizar las tendencias económicas y sociales de mediano y largo plazo de los países latinoamericanos, así como proponer alternativas de desarrollo (Hodara, 1987: 23-28); se convirtió en una propuesta original de varios países latinoamericanos para explicar y tratar de superar sus condiciones de pobreza, pese a que los beneficios fueron efímeros. La gran innovación en las explicaciones fue la llamada "Teoría de la dependencia" desarrollada por Raúl Prebisch, no obstante años más tarde fue severamente cuestionada. Los países de América Latina no lograron superar sus problemas económicos y el pensamiento cepalino quedó desfasado, justo cuando en varias partes del mundo los países más poderosos comenzaron a formar bloques económicos, aprovechando las condiciones de los países menos desarrollados.

Cabe aclarar que los programas como CEPAL y los bloques económicos son diferentes, el primero de ellos busca "medidas de apoyo" a ciertos países, el segundo se crea con otros intereses, como fomentar mercados comunes y otro tipo de acuerdos; pero en ambos, quienes dictan las políticas económicas y se benefician son los países más desarrollados, porque son ellos los que establecen las condiciones de los préstamos o las reglas de intercambio comercial. Los bloques económicos fueron creados para que las potencias de Europa, Estados Unidos y Japón - se ubicaran en espacios ventajosos en el comercio mundial; y para que los países cuyas economías son débiles se insertaran en él o superaran su pobreza y marginación social. Aunque su origen no es tan nuevo, ya que desde siglos atrás se firmaban tratados internacionales entre diversos países para formar alianzas políticas, mercantiles o de otro tipo, los que surgen en la segunda mitad del siglo XX tienen una tendencia más económica.

En el caso de Latinoamérica, en 1960 se formó la Asociación Latinoamericana de Comercio (ALALC) con doce países miembros: Argentina, Brasil, Chile, México, Paraguay, Perú, Uruguay, Colombia, Ecuador, Venezuela, Bolivia. Años después, en 1980, se transformó en Asociación Latinoamericana de Integración (ALADI), cuyos miembros son: Argentina, Bolivia, Brasil, Chile, Colombia, Cuba, Ecuador, México, Paraguay, Perú, Uruguay, Venezuela. La finalidad de esta nueva organización fue el de hacer frente común a diversos problemas que aquejaban a los integrantes del bloque; se tomaron las medidas necesarias como para que en un tiempo de doce años se llevara a cabo la disminución de impuestos y restricciones a los intercambios comerciales recíprocos entre los miembros. Como este proyecto, en otras partes del mundo han surgido algunos similares.

Estados Unidos y Canadá firmaron un convenio en 1989, al que en 1991 se añadió México: Asociación de Libre Comercio de Norteamérica, el cual en 1994 se transformó en Tratado de Libre Comercio de América del Norte, TLCAN. También en 1989 se conformó otro bloque llamado Asian Pacific Economic Cooperation, APEC, conformado por 21 miembros: Australia, Nueva Zelanda, Malasia, Filipinas, Indonesia, Taipei, Brunei, Papua-Nueva Guinea, Tailandia, Hong Kong, Vietnam, Singapur, China, Rusia, Corea del Sur, Japón, Canadá, Estados Unidos, México, Perú y Chile. Algunos países de Sudamérica han conformado el MERCOSUR; casi todos los países europeos más desarrollados crearon inicialmente la Comunidad Económica Europea, CEE, que después se transformó en Comunidad Europea y posteriormente en Unión Europea, UE, el organismo de este tipo con mayores alcances y logros a esfera mundial; también hay otros en el resto de Asia, Europa, Sudamérica e incluso en África.

El objetivo de estos planes es conformar bloques económicoscapaces demantenerun mercadocomún, con 
reducción de aranceles en los productos establecidos en el tratado e intercambio de tecnología, principalmente; entre los acuerdos se consideran también apoyos mutuos en caso de desastres ocasionados por fenómenos naturales, frente común a problemas como inseguridad, narcotráfico, desnutrición, hambrunas, epidemias, analfabetismo, pornografía infantil, escasez de agua, inmigración; ahora también se añaden terrorismo y guerrillas, etcétera.

Debemos mencionar que detrás de varios de estos convenios se ocultan otros intereses. No podemos negar que algunos como UE han generado muchos beneficios a los países miembros, por ejemplo, se han firmado acuerdos que permiten el intercambio comercial con escasas restricciones, se ha creado una moneda común, se puede viajar de un país a otro con un solo documento de identificación, etc. (Delgadillo, 1993: 15-16). Aunque se han generado una serie de discusiones como conflictos de identidad, validez de las soberanías nacionales, discriminación racial, problemas económicos... (Saxe-Fernández, 1995; Batiz y Poo, 1995). También debemos agregar algo que es muy importante, la mayor parte de los miembros de este bloque tienen características socioeconómicas y políticas similares, como lo demuestran los índices y tasas de desarrollo; sin embargo, hay naciones cuya pertenencia al bloque es cuestionada, como Turquía, Macedonia, España, entre otros.

Varios proyectos, en cambio, tienen enormes desigualdades entre los países miembros; por ejemplo, el TLCAN. Mientras Estados Unidos y Canadá son países con muy altos niveles de desarrollo: infraestructura similar, niveles de acceso a salud, educación, transporte, vivienda, salarios muy parecidos, industrias altamente tecnificadas, instituciones políticas y gubernamentales bastantes confiables, etc., México es un país cuyos índices de desarrollo son modestos, por no decir, raquíticos. El papel jugado por México en este bloque es el de abastecedor de materias primas y comprador de manufacturas, lo cual no es una situación ventajosa, sino más bien de subordinación y dependencia.

Los serios problemas de pobreza y marginación social de los países de Centroamérica y el sur sureste de México los colocan en condiciones de desventaja ante cualquier convenio de este tipo. Además, la gran influencia económica de Estados Unidos en el continente americano se ve amenazada por CEE y algunos países asiáticos como China y Japón; de ellos es conocido que en esta área hay suficientes energéticos como para sostener sus industrias en las próximas décadas, además de la gran riqueza natural que guardan estas tierras y que han sido poco explotadas.

Estados Unidos desde principios del siglo XIX proclamó la famosa doctrina Monroe, en la cual se señala: América para los americanos. En el discurso la frase se refiere a que los países americanos son los únicos con derechos sobre el continente y ningún país de otra parte del mundo tiene derecho a intervenir en sus asuntos ni invadirlos por cualquier circunstancia. En realidad, quiere decir: América para Estados Unidos. Desde finales del siglo XIX, este país extendió su influencia al continente y durante el siglo XX se autodenominó su protector; es esta nación quien dicta las políticas económicas, legitima los regímenes políticos, no solo de América sino también de casi todo el mundo (Aguirre, 2001: 53; Bulmer-Thomas, 1994). Desde su independencia se ha autoproclamado como el paladín de la libertad y la justicia, el árbitro mundial en los conflictos internacionales y protector de los países débiles y pobres. Sin embargo, su objetivo primordial es someter a estas endebles naciones a sus intereses. Puede derribar regímenes políticos argumentando que son antidemocráticos, protectores de terroristas o fomentadores del narcotráfico, cuando lo que en realidad desea es aprovechar las materias primas de estos pueblos y países.

México y Centroamérica pagan el "pecado" de ubicarse cerca de esta gran potencia, ya que este vecino incómodo interviene abiertamente en sus asuntos 
internos al condicionar los apoyos financieros. La gran competencia que representan UE y China y Japón, por ser bloques económicos bastante fuertes, ha obligado a Estados Unidos a tomar medidas de precaución. En estos momentos se está posicionando de las reservas de energéticos más importantes del mundo, como las de medio oriente, y su siguiente objetivo pueden ser México y Centroamérica (Aguirre, 2001: 54; Delgadillo, 1993: 42-48).

\section{El Proyecto Mesoamérica}

Por lo señalado anteriormente, no es inocente la aparición de una nueva propuesta. Se pretende sustentar la legitimidad en un argumento histórico; para ello se recurre al concepto esgrimido por Paul Kirchhoff: "Mesoamérica". En otras palabras, se intenta presentar la idea de que el Proyecto de Integración y Desarrollo de Mesoamérica, conocido también como Proyecto Mesoamérica, PM, es un tratado entre los países que conforman la región por el hecho que comparten una historia, espacio y rasgos culturales comunes, y lo han propuesto para superar los graves problemas de marginación social y pobreza que los agobian. A simple vista, la utilización del concepto Mesoamérica para referirse a este espacio hace alusión a la compatibilidad histórica, espacial y cultural. Sin embargo, suele "ignorarse" el papel jugado por la región a lo largo de cinco siglos: el de manzana de la discordia. Teniendo este contexto histórico, podemos percibir que PM es un nuevo plan para aprovechar la ubicación estratégica y sobre todo los recursos naturales de la zona.

Para comprender mejor la línea trazada en esta exposición, es necesario conocer qué es PM, cuándo se propuso, quienes lo promueven y por qué, a quiénes y cómo beneficiarán, qué hay detrás de él, qué costos tendrá para los países que lo conforman y cuál es el papel que Estados Unidos y algunas potencias europeas y asiáticas desempeñarán. Con la intención de responder algunas de estas preguntas acudimos a la página electrónica oficial del Proyecto Mesoamérica que se encuentra en el portal de Internet de la Secretaría de Relaciones Exteriores de México — http://portal2.sre. gob.mx/mesoamerica - y nos encontramos varias de las respuestas, aunque siendo críticos podemos ver que están elaboradas desde la perspectiva oficial, es decir, solo se mencionan sus objetivos y metas, exaltando los beneficios para los pueblos involucrados.

De manera que PM en su origen fue presentado como una propuesta de integración económica para la región mesoamericana - exceptuando casi todo el occidente y la zona principal del centro de México-. La conforman los estados del sur sureste mexicano de Puebla, Guerrero, Veracruz, Oaxaca, Yucatán, Campeche, Quintana Roo, Tabasco y Chiapas, y los siete países de América Central: Guatemala, Belice, Honduras, Nicaragua, El Salvador, Costa Rica y Panamá y Colombia (ver mapa 2).

El 15 de junio de 2001, en San Salvador, El Salvador, durante la sesión Cumbre Extraordinaria del Mecanismo de Diálogo y Concertación de Tuxtla, por los jefes de Estado y de Gobierno de los ocho países señalados, se lanzó el Plan Puebla Panamá, PPP, donde uno de los principales promotores fue el ex presidente mexicano Vicente Fox Quesada (Barceló, 2002: 24). Cabe mencionar que este proyecto inició con el ex presidente Ernesto Zedillo, a raíz de la entrada en vigor en 1994 del TLCAN firmado con Estados Unidos y Canadá en el sexenio de Carlos Salinas de Gortari, primer paso para la conformación del Área de Libre Comercio de las Américas, ALCA, al cual nos referiremos más adelante.

Desde la perspectiva oficial, el PPP se proponía lograr una integración económica que promoviera intercambios comerciales con pocas restricciones arancelarias, mejorara la infraestructura de la región, abriera oportunidades de trabajo y aprovechara racionalmente los recursos, todo esto, para lograr un desarrollo sustentable y equilibrado. Los beneficiarios del PPP serían los 64,000,000 de habitantes de la zona —28 millones en el sur sureste de México y 36 millones 
en Centroamérica-, porque a decir de los promotores son herederos de una cultura milenaria y comparten historia, cultura, tradiciones y valores, viven en un espacio geográfico similar y poseen aspiraciones e intereses comunes. Para llevar a cabo lo pactado en PPP se establecieron ocho estrategias, cada una de las cuales sería coordinada por un país miembro:

1. Iniciativa Mesoamericana de Desarrollo Sustentable

2. Iniciativa Mesoamericana de Desarrollo Humano

3. Iniciativa Mesoamericana de Prevención y Mitigación de Desastres Naturales

4. Iniciativa Mesoamericana de Promoción del Turismo

5. Iniciativa Mesoamericana de Facilitación del Intercambio Comercial

6. Iniciativa Mesoamericana de Integración Vial

7. Iniciativa Mesoamericana de Interconexión Energética

8. Iniciativa Mesoamericana de Integración de los Servicios de Telecomunicaciones

Con estas disposiciones se pretendía que los países de la zona aprovecharan de manera racional los recursos naturales; mejoraran los servicios sociales básicos de la población más necesitada; tomaran las medidas viables para prevenir los desastres por fenómenos naturales o al menos para minimizar los daños; se beneficiaran del turismo internacional, difundiendo la gran cantidad de sitios arqueológicos y los majestuosos paisajes naturales de la región; redujeran los costos de las operaciones mercantiles entre los países miembros y promovieran a las pequeñas y medianas empresas de la zona; mejoraran la infraestructura vial para facilitar el comercio, tránsito de personas y se aminoraran los gastos de transporte; promovieran las inversiones en el sector eléctrico, aprovechando la gran cantidad de ríos capaces de generar energía y se redujera el precio de la electricidad; $y$, finalmente, buscaran tener acceso a los servicios de telecomunicaciones que los unieran a las grandes redes de comunicación digital y satelital (Cedeño, 2002: 15, 58-59).

La planeación de PPP vislumbraba obtener beneficios a mediano plazo; es decir, para 201502020 se pronosticaba que los países miembros hubieran mitigado los índices de desarrollo que les eran desfavorables, poseyeran una infraestructura que les permitiera llevar a cabo las iniciativas pactadas, fueran gobernados por regímenes con democracias consolidadas, hubieran disminuido sus deudas externas y estuvieran comunicados con las más altas tecnologías. En otras palabras, que todos los habitantes de la región tuvieran acceso a los servicios de educación, salud, transporte, mejores salarios y, sobre todo, que estos países no tuvieran problemas de hambre, conflictos raciales o desigualdad entre géneros, y estuvieran insertos en los mercados globales.

En estos acuerdos se creó una Comisión Ejecutiva del PPP, que se integraba por los comisionados presidenciales y el designado por el primer ministro de Belice, que sería la encargada de coordinar las iniciativas y propuestas anexas al proyecto principal, así como de llevar a cabo un seguimiento de ejecución. También se formó un Grupo Técnico Interinstitucional para asesorar y apoyar las iniciativas de PPP, donde destacan el Banco Centroamericano de Integración Económica. BCIE; el Banco Interamericano de Desarrollo, BID; la Comisión Económica para América Latina y el Caribe, CEPAL; el Instituto Centroamericano de Administración de Empresas, INCAE; la Secretaría de Integración Económica Centroamericana, SIECA; la Secretaría General del Sistema de la integración Centroamericana, SG-SICA; la Corporación Andina de Fomento, CAF; el Instituto Español de Comercio Exterior, ICEX; el Instituto Español de Crédito Oficial, ICO; y el Programa de Naciones Unidas para el Desarrollo, PNUD.

En este mismo documento oficial del PPP, se especificaba que este era un primer paso antes de llegar a la conformación de ALCA. Este último plan ha sido promovido por Estados Unidos y se anunció en la 
Cumbre de Presidentes del Continente en Miami, en 1994; en la cumbre celebrada en Canadá, 2001, se tomó la decisión de celebrar la firma en 2005. En apariencia, ALCA es un megaproyecto de bloque económico del continente americano para crear un mercado libre de bienes y servicios entre los países miembros, teniendo como beneficios primarios la reducción de impuestos a las importaciones y la promoción de inversiones privadas internacionales.

Hasta aquí, hemos visto el propósito inicial con la revisión de los documentos de PPP, la cual nos ha dejado aproximarnos a algunas de las respuestas a las preguntas planteadas. Sin embargo, con un poco de sentido común, junto a lo que hemos señalado a lo largo de este escrito, nos damos cuenta que esto no es sino un mero discurso que justifica un objetivo en gran medida alejado de la realidad de los habitantes de la región, y que ha sido aprobado por los gobiernos de los países involucrados más por presiones externas que por el interés de superar los problemas que los aquejan (Barreda, 2001: 139-166; Cedeño, 2002: 62).

En abril de 2007 se reunieron los jefes de Estado de los países mencionados con la finalidad de hacer una revisión de los logros de PPP, incorporando algunos cambios sugeridos por algunos organismos internacionales. Posteriormente, en junio de 2008, durante la X Cumbre del Mecanismo de Diálogo y Concertación de Tuxtla en Villahermosa, Tabasco, en donde estuvieron presentes los jefes de Estado de los ocho países miembros a los que se agregó el de Colombia, se tomó la decisión de reestructurarlo y crear el Proyecto de Integración y Desarrollo de Mesoamérica o Proyecto Mesoamérica, PM, haciendo modificaciones estructurales al planteamiento original (Proyecto Mesoamérica: Cumbre de Campeche [2007] y Cumbre de Villahermosa [2008]; ver también documentos oficiales de la X Cumbre de Jefes de Estado y de Gobierno del Mecanismo de Diálogo y Concertación de Tuxtla [2008] y XI Cumbre de Jefes de Estado y de Gobierno del Mecanismo de Diálogo y Concertación de
Tuxtla [2009]). Se menciona que durante la etapa de PPP, 2001-2008, se lograron importantes avances en cuanto a infraestructura - transporte, telecomunicaciones, y otros servicios- y se hacía notar que en esta nueva fase se pretende consolidar "proyectos de alto impacto social en áreas de salud, medio ambiente, desastres naturales y vivienda, representando con ello una gran oportunidad para que los países cooperantes pudieran participar con su experiencia y recursos a la consolidación de las prioridades de la región" (Proyecto de Integración y Desarrollo de Mesoamérica: El PPP: avances, retos y perspectivas. Evolución del Plan Puebla Panamá hacia un Proyecto de Integración y Desarrollo de Mesoamérica [2008]).

El PPP que fue presentado por el gobierno federal de México parecía ser la solución a todos los problemas de la región sur sureste. Y no solo eso, fue diseñado para hacer creer a los habitantes de esta zona y el país, y también a los centroamericanos, que los graves problemas de pobreza y marginación social se resolverían llevando a cabo las iniciativas firmadas por los gobiernos de estas naciones. La realidad es otra, porque esta propuesta tiene muchos puntos en contra, no solo las enormes diferencias socioeconómicas de estos países sino también la condición de dependencia que han tenido respecto a las grandes potencias europeas y Estados Unidos desde hace poco más de cinco siglos.

El surgimiento de este proyecto no fue originado a partir de la iniciativa de los gobiernos de estas naciones para atacar de manera conjunta los problemas que los aquejan, sino del gobierno mexicano impulsado por el de Estados Unidos. Hay algo más allá de crear un mercado común entre ellos, combatir la pobreza y la marginación, erigir una infraestructura para mejorar las comunicaciones terrestres e intercambio de mercancías o consolidar sus regímenes políticos con instituciones confiables y democráticas, por el solo hecho de compartir un área geográfica similar, rasgos culturales e historia. Al analizar la documentación oficial se percibe 
que es un primer paso antes de conformar ALCA, pero ¿cómo pueden introducirse en el comercio internacional a gran escala como lo hacen Estados Unidos o Canadá, teniendo los países centroamericanos y el sur sureste de México tan bajos índices de desarrollo e incluso las demás naciones latinoamericanas? La respuesta es simple: para aportar sus recursos naturales, como biodiversidad, agua, minerales y mano de obra no calificada.

Sin duda, las condiciones socioeconómicas de la zona mesoamericana la colocan en posición de desventaja frente a países como Estados Unidos, Japón, China o UE. Por lo mismo, PPP —en adelante PM - es uno de los primeros pasos antes de crear ALCA. Lo que se pretende es tratar de homogenizar esta zona - la más pobre del continente- a los niveles del norte de México y los de los otros países de América Latina, de modo que cuando se ponga en marcha el megaproyecto se facilite la ejecución de las iniciativas propuestas en éste, que serán ventajosas para Estados Unidos y en menor medida para Canadá (Dos Santos, 2003; Villafuerte, 2007).

En la actualidad, el vecino incómodo del norte está siendo severamente cuestionado por la comunidad internacional debido a la política exterior de los últimos años - como la representada por el ex presidente George Walker Bush-, cuyo objetivo es apoderarse arbitrariamente de las reservas de energéticos más importantes del mundo como las de Medio Oriente, bajo la excusa de combatir el terrorismo de esta zona y que representa un peligro para la paz mundial. En el continente americano no puede aplicar esta misma política, por eso se argumenta que es necesario combatir la pobreza y la marginación social de los países centroamericanos y el sur sureste mexicano.

Curiosamente se margina a Cuba, mientras que para las otras naciones del Caribe se han establecido programas de ayuda humanitaria. En este punto podemos objetar que si el argumento es acabar con la pobreza de los países latinoamericanos, ipor qué no se considera al Caribe -incluyendo Cuba- en el PM, será porque no cuenta con la riqueza natural del área mesoamericana? Si se está pensando en crear mejores estándares de vida para los habitantes de América Latina, ipor qué no se anula el bloqueo económico a Cuba, o se desechan las iniciativas de reducir el envío de dinero verde de los cubanos radicados en Estados Unidos a sus familiares que viven en la isla o la cantidad de dólares gastados por los visitantes estadounidenses en ella?

Es importante aclarar que somos concientes de que el Caribe no forma parte del concepto histórico de Mesoamérica esgrimido por Kirchhoff, pero lo mencionamos porque lo que está a discusión no es el concepto mismo, sino el argumento presentado por los promotores de PM, ALCA, y otros tratados similares de combatir los niveles de pobreza de los países latinoamericanos; porque de ser cierto este planteamiento, no se excluiría ninguna nación del continente aunque no forme parte de la masa continental o de una definición histórica.

Detalles como estos son los que hacen dudar de las buenas intensiones de PM, y por lo mismo han provocado que tanto en México como en Centroamérica se estén organizando grupos para vigilar, criticar y oponerse a este plan (Ceja, 2003; Bartra, 2004). Entre ellos podemos citar algunas comunidades indígenas y campesinas de la zona, encabezadas por intelectuales y ONG; organizaciones de agricultores, ganaderos, pescadores y empresarios locales; el EZLN; algunos partidos y organizaciones políticas, entre los principales.

Para los críticos de PM, este es un conjunto de inversiones en obras de infraestructura — vial, aérea, marítima - para facilitar el traslado de mercancías que llegan de Estados Unidos o para la salida de las materias primas producidas por los países de la zona. No hay programas de industrialización para dicha zona, sino para el establecimiento de maquilas, las cuales aprovecharán al máximo la biodiversidad en el área y la mano de obra no calificada (Barreda, 2001: 166-178; Bartra, 2001: 18, 35-36; Preciado y Villarruel, 
2006: 26-28). También señalan que si entrara en vigor el megaproyecto ALCA, quienes más se beneficiarían serían las empresas transnacionales estadounidenses, las cuales se apropiarían de muchos de los servicios públicos como electricidad, agua potable, salud, educación y otros; además, los beneficios generados por estos lucrativos negocios saldrían del país para depositarse en los grandes bancos del vecino del norte. Es decir, para estos opositores a PM el objetivo de Estados Unidos es apropiarse de los recursos naturales de la región, convirtiendo a la zona mesoamericana en su mercado de abasto.

Algo tienen de razón los opositores a PM. La escasa industrialización de los países de América Latina incluyendo la región mesoamericana-, es un punto que juega en contra de ellos al tratar de insertarse en los bloques económicos de las grandes potencias. El papel que desempeñarán será el de exportadores de materias primas y compradores de manufacturas. Las condiciones de estos tratados siempre jugarán a favor de los países más desarrollados, porque al contar con industrias con tecnología de punta, economías más fuertes e instituciones más estables, dictarán las políticas y medidas que deberán seguir las naciones más pobres, cuya industria está poco tecnificada, sus economías son débiles y sus instituciones inestables.

El PM y similares - y por ende ALCA - son propuestas que poco beneficiarán a los países latinoamericanos debido a que no consideran prioritaria la industrialización tecnificada sino simples maquilas; no entran en los planes países como los de las Antillas, sino los que cuentan con recursos naturales que garanticen las inversiones — como los del área mesoamericana o sudamericana-; se presta poca atención a los inversionistas locales y se favorecen los capitales transnacionales; al unificar los criterios de calidad de educación y vida, no se salvaguardan las diferencias culturales o ideológicas, porque solo entran en sus propósitos aquellos que se apeguen a las normas establecidas (Moguel, 2001: 333-347).
Por lo anterior, son cuestionables los beneficios si se crea un área de libre comercio en todo el continente americano, en el sentido de que las naciones más pobres continuarán siendo marginadas y se les impondrán condiciones de subordinación en las negociaciones arancelarias, en los procesos de industrialización y en sus políticas internas; sólo sería viable si todos los países tuvieran índices de desarrollo económico y social similares. Desde esta perspectiva, PM no es más que un nuevo proyecto para aprovechar la ubicación estratégica de los países de la región y la gran riqueza natural con la que cuentan.

Recursos como el petróleo, agua, tierras de cultivo, bosques y selvas no son nada despreciables para potencias como Estados Unidos, que necesitan una reserva de energéticos a mediano plazo para garantizar su papel preponderante en el mundo. El gran vecino del norte reconoce el peligro que representan UE, Japón o China para su pretendida hegemonía mundial como la potencia política, militar y económica; sabe del interés que estos tienen en expandir sus mercados hacia varias partes del mundo, incluyendo América Latina, por tanto, le urge firmar acuerdos que garanticen que la riqueza de estos países únicamente sean para él.

La multicitada globalización no es más que una nueva expansión estratégica de las grandes potencias. Es decir, una redistribución de colonias para abastecerse de materias primas y como futuros compradores de manufacturas, así también una reconfiguración del mapa geopolítico mundial entre las potencias y sus aliados que garanticen tal expansión. Una vez más, México y Centroamérica se encuentran en medio de las disputas de las grandes potencias que buscan aprovechar su ubicación estratégica entre el Pacífico y el Atlántico y la gran riqueza natural que guardan en sus entrañas.

Como sucedió con España, que buscaba rutas más cortas para comerciar con oriente; o la defensa que hicieron los propios españoles frente a los piratas 
de Francia, Inglaterra y Holanda; o el "amparo" que brindó Estados Unidos a sus "hermanos americanos" ante las amenazas de los europeos; o la lucha contra el comunismo que hizo Estados Unidos en América Latina, para salvaguardarla del desorden; hoy PM se vislumbra más como una nueva disputa frente al gran expansionismo neoliberal, que como esperanza para superar la pobreza y marginación social del área.

\section{Epílogo}

Es importante señalar que ya empieza a discutirse sobre PM en los medios académicos, es decir, el número de libros publicados en torno a este proyecto aún son pocos, aunque sí hay varias decenas de artículos editados en revistas o sitios de Internet. Ya escuchamos debates sobre la viabilidad del mismo, las consecuencias para los países miembros y los tranfondos que hemos esbozado en esta reflexión.

Todavía hay una gran desinformación entre la sociedad civil. Quienes han tomado la iniciativa para analizar el PM son algunos políticos, académicos, ONG y uno que otro enterado del asunto; varios de estos se han encargado de organizar foros y campañas de información a comunidades indígenas, campesinas, agrupaciones de obreros, estudiantiles, ecologistas, defensores de derechos humanos, etc., esto se refleja en las numerosas páginas de Internet en contra de PM, que superan a las que lo apoyan.

En el discurso de los muchos "Pppfóbicos" — como los denomina Armando Bartra; aunque ahora serían "PMfóbicos"-, se deja sentir una sobre ideologización antineoliberal que raya en la paranoia, más que análisis concienzudo de lo que hay en torno al proyecto. Los ánimos están ardiendo y dan la impresión de que ciegan las palabras y enmudecen las mentes de muchos de los críticos. Menciono esto porque el objetivo de el presente escrito no es resistirse a PM por el simple hecho de oponerse a toda iniciativa de los gobiernos, sino detener la mirada en el argumento que se pretende vender a los mexicanos y centroamericanos. Desde nuestro punto de vista, PM es un intento más para aprovechar la ubicación estratégica y los recursos naturales de la región, idea que hemos reiterado a lo largo de este trabajo.

Analizar PM desde una perspectiva histórica permite comprender la importancia de la región en los convenios de expansión económica de países como Estados Unidos y UE, así como de algunos países asiáticos; invita también a percibir PM como un plan que surge de los intereses de las grandes potencias y no del interés de los gobiernos de la zona para superar los problemas de pobreza y marginación social. Y desde luego, a pensar que suele recurrirse a la historia como justificante de una propuesta con tintes económicos para otorgarle mayor legitimidad, tal como se ha hecho al acudir a un concepto histórico como "Mesoamérica", en el planteamiento oficial y los documentos firmados por los gobiernos y jefes de Estado de los países involucrados.

Hemos pretendido con esta sencilla reflexión poner sobre la mesa algunos detalles que permitan pensar el Proyecto Mesoamérica desde otra óptica, no necesariamente política e ideologizada; corresponde a los expertos en el tema, que están estudiando la viabilidad, disyuntivas y alternativas del mismo, considerar el punto de vista histórico en sus análisis y explicaciones.

\section{Notas}

${ }^{1}$ Este trabajo es producto de los primeros resultados del proyecto "La sociedad fronteriza del medio Usumacinta: economía, desarrollo y cambio climático (1940-2007)", realizado durante la estancia posdoctoral en El Colegio de la Frontera Sur Unidad Villahermosa, entre julio de 2009 y junio de 2010.

2 Precisando un poco, con el término "Corona española" nos referimos a la Corona de Castilla y Aragón (dinastía de los Habsburgo).

${ }^{3}$ Mencionamos el Caribe y consideramos la parte de México y Estados Unidos — actuales— que da al Golfo 
de México, las Antillas y América Central, además de una pequeña parte de Colombia y Venezuela. En este caso queremos destacar el papel de la zona que conocemos como Centroamérica y el sureste de México - Golfo de México y la península de Yucatán.

4 Muchos de los ingleses lo hicieron con el consentimiento de sus monarcas, quienes les permitieron realizar operaciones ilegales en las rutas españolas del Nuevo Mundo, por ello se les conoce como corsarios, algunos marinos franceses recibieron apoyos similares. Sin embargo, los que no, se les conoció como filibusteros - trabajaban para su propio beneficio y deambulaban por los maresbucaneros - vivían en islas y comerciaban con pieles de ganado que los españoles abandonaban en ellas, aprovechaban ocasiones propicias para atacar puertos y ciudades, ocasionalmente barcos y eran los piratas más sangrientos-y pichilengues - término utilizado para referirse a los piratas holandeses; estos actuaron más en el Pacífico que en el Caribe.

${ }^{5}$ Sobre las actividades ilícitas de comercio en el Caribe es interesante el trabajo de Romano, en donde se explica con cifras bastante aceptables las "sangrías" que producía el contrabando y la piratería a la economía de la Corona española (Romano, 1998: 35-101).

${ }^{6}$ Debemos precisar que la situación de Panamá es mucho más compleja, por lo que remitimos al lector a la bibliografía citada.

${ }^{7}$ A la que luego se agregó el Caribe, transformándose en CEPALC.

${ }^{8}$ Véase con reservas la obra de Víctor Manuel Barceló R., op. cit., la cual nos presenta una visión bastante apegada a la oficial de PPP, aunque nos hace un desglose cuidadoso y con cifras de lo que se propone con este proyecto.

9 Nótese aquí cómo se recurre al concepto histórico elaborado por Paul Kirchhoff para argumentar este proyecto económico.

${ }^{10}$ El citado Compendio de Información de la región PueblaPanamá es uno de los muchos estudios que se han hecho a la zona en los diversos rubros - geográficos, económicos y sociales-, para tener la información básica de los recursos con los que cuenta y en menor medida para tener conocimiento de los problemas que la aquejan.

${ }^{11}$ El primer autor hace una cuidadosa revisión de diversos tipos de documentos oficiales que anteceden y de alguna manera influyen en la elaboración de PPP. Entre ellos el principal es un texto hecho en México - casi como marca registrada - por Santiago Levy, Enrique Dávila y Georgina Kessel titulado "El sur también existe: un ensayo sobre el desarrollo regional de México" en julio de 2000, y que hace uso de información estadística oficial muy precisa y clara para diagnosticar los principales problemas del sur sureste de México y sugerir posibles alternativas de desarrollo, pero ignorando el contexto histórico de la región.

${ }^{12}$ Basta con observar los programas de PM, los cuales están orientados a mejorar la infraestructura de transporte, energía, telecomunicaciones, facilitación comercial y competitividad, salud, vivienda y mejoramiento de las estrategias para la prevención de desastres y cuidado del medio ambiente (Proyecto de Integración y Desarrollo de Mesoamérica: Informe Ejecutivo 2008-2009).

\section{Bibliografía}

Aguirre Rojas, Carlos Antonio (2001), América Latina. Historia y presente, México: Red Utopía/Jitanjáfora Morelia Editorial.

Barceló Rodríguez, Víctor Manuel (2002), El Plan PueblaPanamá. ¿Integración o segregación?, ies útil a los pueblos hermanos?, ¿decisión imperial?, México: Universidad Juárez Autónoma de Tabasco/Fundación Academia Metropolitana.

Barreda Marín, Andrés (2001), "Los peligros del Plan Puebla-Panamá”, en Armando Bartra (coord.), en Mesoamérica: los ríos profundos. Alternativas plebeyas al Plan Puebla-Panamá, México: Instituto Maya/El Atajo Ediciones/Fomento Cultural y Educativo/ 
RMALC/Equipo Pueblo/CASIFOP/ANEC/CCECAM/ SEMAPE/CEN-PRD, pp. 133-214.

Bartra, Armando (2001), "Sur. Megaplanes y utopías en la América equinoccial", en Armando Bartra (coord.), en Mesoamérica: los ríos profundos. Alternativas plebeyas al Plan Puebla-Panamá, México: Instituto Maya/El Atajo Ediciones/Fomento Cultural y Educativo/RMALC/ Equipo Pueblo/CASIFOP/ANEC/CCECAM/SEMAPE/ CEN-PRD, pp. 13-132.

Batis Muñoz, Ana I. y Poo Hurtado, Jorge (1995), "Globalización económica y barbarie: el caso de los grupos étnicos”, en José Luis Calva (coord.), Globalización y bloques económicos. Realidades y mitos, México: Centro Universitario de Ciencias Sociales y Humanidades/Benemérita Universidad Autónoma de Puebla: Programa de Estudios de Economía Internacional.

Bulmer-Thomas, Víctor (1994), La historia económica de América Latina desde la Independencia, México: Fondo de Cultura Económica.

Calderón Quijano, José Antonio (1996), Las fortificaciones españolas en América y Filipinas, España: Editorial MAPFRE.

Cano, Wilson (2003), "América Latina: industrialización, crisis y neoliberalismo", en Juan Manuel Durán Juárez, Ofelia Woo Morales y Jorge Ceja Martínez (coords.), La globalización en América Latina a la luz del nuevo milenio, México: Universidad de Guadalajara.

Capdepont Ballina, Jorge Luis (2009), "Del campo a la ciudad: Tabasco y sus transformaciones económicas (1945-2008)", en Historia política contemporánea de Tabasco (1958-2008), tomo II, Carlos Enrique Ruiz Abreu y Andrés Fábregas Puig (coords.), México: Gobierno del Estado de Tabasco, pp. 1-115.

Cedeño del Olmo, Manuel (2002), Participación social y gobernabilidad en Tabasco en el marco del Plan PueblaPanamá (avance de investigación), México: Universidad Juárez Autónoma de Tabasco/PROMEP.
Ceja Martínez, Jorge (2003), “La globalización indeterminada: Por los caminos de Davos, La Realidad y Porto Alegre", en Juan Manuel Durán Juárez, Ofelia Woo Morales y Jorge Ceja Martínez (coords.), La globalización en América Latina a la luz del nuevo milenio, México: Universidad de Guadalajara.

Compendio de Información de la Región Puebla-Panamá (2001), $2^{2}$ e edición, México: Instituto Nacional de Estadística, Geografía e Informática.

Delgadillo Macías, Javier (1993), El desarrollo regional de México ante los nuevos bloques económicos, México: UNAM, Instituto de Investigaciones Económicas.

Dos Santos, Theotonio (2003), "La economía mundial en el nuevo siglo", en Juan Manuel Durán Juárez, Ofelia Woo Morales y Jorge Ceja Martínez (coords.), La globalización en América Latina a la luz del nuevo milenio, México: Universidad de Guadalajara.

Fonseca Corrales, Elizabeth (1992), "Economía y sociedad en Centroamérica (1540-1680)", en Historia General de Centroamérica, Madrid, España: Editorial Siruelas.

García Fuentes, Lutgardo (1980), El comercio español con América (1650-1700), España: Excma. Diputación Provincial de Sevilla/Escuela de Estudios Hispanoamericanos de Sevilla: Consejo Superior de Investigaciones Científicas.

García Ruiz, Ramón (1945), El canal de Panamá: una epopeya de nuestro siglo. Síntesis histórico-geográfica, México: Secretaría de Educación Pública.

Gutiérrez Canet, Agustín (2003), "América Latina en la nueva geopolítica mundial”, Juan Manuel Durán Juárez, Ofelia Woo Morales y Jorge Ceja Martínez (coords.), La globalización en América Latina a la luz del nuevo milenio, México: Universidad de Guadalajara.

Hodara, Joseph (1987), Prebisch y la CEPAL. Sustancia, trayectoriay contexto institucional, México: El Colegio de México.

Ibarra, Antonio (1999), "El mercado no monetario de la plata y la circulación interior de importaciones en la Nueva España. Hipótesis y cuantificación de un modelo regional: Guadalajara, 1802-1803", en 
Margarita Menegus Bornemann (coord.), Dos décadas de investigación en historia económica comparada en América Latina. Homenaje a Carlos Sempat Assadourian, México: El Colegio de México/Centro de Investigaciones y Estudios Superiores en Antropología Social/Instituto Doctor José María Luis Mora/UNAM, Centro de Estudios Sobre la Universidad.

Jiménez Moreno, Wigberto (1979), “Vida y acción de Paul Kirchhoff”, en Barbro Dalhgren (coord.), Mesoamérica. Homenaje al doctor Paul Kirchhoff, México: SEP/INAH, pp. 11-25.

Kirchhoff, Paul (2009), "Mesoamérica. Sus límites geográficos, composición étnica y caracteres culturales", [en línea], Al fin liebre ediciones digitales, Xalapa, Veracruz: Consultado el 17 de octubre de 2010. Aparece en http://.alfinliebre.blogspot.com

Kuntz Ficker, Sandra (1999), "Ferrocarriles y mercado de productos agrícolas en el porfiriato. El impacto de las tarifas ferroviarias", en Margarita Menegus Bornemann (coord.), Dos décadas de investigación en historia económica comparada en América Latina. Homenaje a Carlos Sempat Assadourian, México: El Colegio de México/Centro de Investigaciones y Estudios Superiores en Antropología Social/Instituto Doctor José María Luis Mora/UNAM, Centro de Estudios Sobre la Universidad.

Lowell, George W. (1990), Conquista y cambio cultural. La sierra de los Cuchumatanes de Guatemala. 1500-1821, Guatemala: CIRMA/Plumsock Mesoamerican Studies.

MacLeod, Murdo J. (1980), Historia socio-económica de la América Central Española. 1520-1720, Guatemala: Editorial Piedra Santa.

Moguel, Julio (2001), "Claroscuros del Plan PueblaPanamá. De cómo se escamotean los derechos indios y se traslada el debate a los presuntos temas del desarrollo", en Armando Bartra (coord.), en Mesoamérica: los ríos profundos. Alternativas plebeyas al Plan Puebla-Panamá, México: Instituto Maya/El Atajo Ediciones/Fomento Cultural y Educativo/RMALC/
Equipo Pueblo/CASIFOP/ANEC/CCECAM/SEMAPE/ CEN-PRD, pp. 331-347.

Moneta, Carlos J. y Quenan, Carlos (comp.) (1998), Las reglas del juego. América latina, globalización y regionalismo, Buenos Aires, Argentina: Ediciones Corregidor.

Panadero Moya, Miguel y Czerny, Miroslawa (coords.) (1991), América Latina: regiones en transición, España: Ediciones de la Universidad de Castilla-La Mancha.

Pérez Brignoli, Héctor (1999), "Transformaciones del espacio centroamericano", en Marcelo Carmagnani, Alicia Hernández y Ruggiero Romano (coords.), Para una historia de América II. Los nudos 1, México: El Colegio de México/Fondo de Cultura Económica.

Pérez-Mallaína, Pablo E. y Torres Ramírez, Bibiano (1987), La Armada del Mar del Sur, Sevilla, España: Escuela de Estudios Hispano-americanos de Sevilla: Consejo Superior de Investigaciones Científicas.

Preciado Coronado, Jaime y Villarruel Mora, Aarón (2006), "México y Centroamérica: hegemonía mundial, resistencias y visibilidad social", en Daniel Villafuerte Solís y Xochitl Leyva Solano (coords.), Geoeconomía y geopolítica en el área del Plan Puebla-Panamá, México: LIX Legislatura de la Cámara de Diputados, CIESAS y Miguel Ángel Porrúa Editores, pp. 19-37.

Rahn Phillips, Carla (1991), Seis galeones para el rey de España. La defensa imperial a principios del siglo XVII, Madrid, España: Alianza Editorial.

Rodríguez Díaz, María del Rosario (coord.) (2000), El Caribe. Intereses geopolíticos y dominación colonial, México: Universidad Michoacana de San Nicolás de Hidalgo, Instituto de Investigaciones Históricas.

Romano, Ruggiero (1998), Moneda, seudomonedas y circulación monetaria en las economías de México, México: El Colegio de México/Fondo de Cultura Económica.

Romero Sotelo, M. Eugenia (1999), "Minería y guerra: financiamiento, distribución y transporte del azogue en la Nueva España (1810-1821)", en Margarita Menegus Bornemann (coord.), Dos décadas de investigación en historia económica comparada en América Latina. Homenaje a Carlos Sempat Assadourian, México: 
El Colegio de México/Centro de Investigaciones y Estudios Superiores en Antropología Social/Instituto Doctor José María Luis Mora/UNAM, Centro de Estudios Sobre la Universidad.

Rosa, Diógenes de la, et al. (1976), El canal de Panamá, México: Fondo de Cultura Económica.

Ruiz Abreu, Carlos Enrique (1994), "La economía de Tabasco en la Colonia”, en Rosa María Romo López (coord.), Historia General de Tabasco, tomo 2, Historia económica, México: Gobierno del Estado de Tabasco: Secretaría de Educación, Culturay Recreación, pp. 3-112.

Ruiz Abreu, Carlos Enrique (2001), Tabasco en la época de los Borbones. Comercio y mercados, 1777-1811, México: Universidad Juárez Autónoma de Tabasco.

Saxe-Fernández, John (1995), "La globalización: aspectos geoeconómicos y geopolíticos”, en José Luis Calva (coord.), Globalización y bloques económicos. Realidades y mitos, México: Centro Universitario de Ciencias Sociales y Humanidades/Benemérita Universidad Autónoma de Puebla: Programa de Estudios de Economía Internacional.

Silva Riquer, Jorge (1999), "El mercado interno novohispano a fines del siglo XVIII. El caso de Michoacán" en Margarita Menegus Bornemann (coord.), Dos décadas de investigación en historia económica comparada en América Latina. Homenaje a Carlos Sempat Assadourian, México: El Colegio de México/ Centro de Investigaciones y Estudios Superiores en Antropología Social/Instituto Doctor José María Luis Mora/UNAM, Centro de Estudios Sobre la Universidad.

Toledo, Alejandro (1995), Geopolítica y desarrollo en el Istmo de Tehuantepec, México: Centro de Ecología y Desarrollo.

Torruco Saravia, Geney (1994), "Historia Económica de Tabasco. Siglo XIX", en Romo López, Rosa María (coord.), Historia General de Tabasco, tomo 2, Historia económica, México: Gobierno del Estado de Tabasco: Secretaría de Educación, Cultura y Recreación, pp. 117-404.
Tudela, Fernando (coord.) (1989), La modernización forzada del trópico: El caso de Tabasco. Proyecto Integrado del Golfo, México: El Colegio de México/Federación Internacional de Institutos de Estudios avanzados/ Centro de Investigación y de Estudios Avanzados el IPN/Instituto de Investigaciones de las Naciones Unidas para el Desarrollo Social.

Vannini, Margarita (editora) (1995), Encuentros con la Historia, Managua, Nicaragua: Instituto de Historia de Nicaragua-CEMCA.

Villafuerte Solís, Daniel (2001), Integraciones comerciales en la frontera sur. Chiapas frente al tratado de Libre Comercio México-Centroamérica, México: UNAM, Programa de investigaciones Multidisciplinarias sobre Mesoamérica y el Sureste.

Villafuerte Solis, Daniel (2007), "Mitos y realidades del Plan Puebla-Panamá", en Juan Póhlenz C. y Juan Manuel Sandoval P. (comps.), El Plan PueblaPanamá, iintegración para el desarrollo?, San Cristóbal de Las Casas, Chiapas, México: Universidad Intercultural de Chiapas/Centro de Estudios de Fronteras y Chicanos, A. C.: Sede Chiapas, pp. 159174.

West, R. C., Psuty, N. P. y Thom, B. G. (1985), Las tierras bajas de Tabasco en el sureste de México, México, Gobierno del Estado de Tabasco.

Wortman, Miles L. (1991), Gobierno y sociedad en Centroamérica. 1680-1840, San José, Costa Rica: Banco Centroamericano de Integración Económica/ EDUCA.

\section{Hemerografía}

Bartra, Armando (2004), "Mesoamericanos. Recalentando una identidad colectiva”, en Memoria. Revista de Políticay Cultura, número 183, México, pp. 34-40.

Camarena Luhrs, Margarita y Valdez Zepeda, Andrés (2002), "El Plan Puebla-Panamá y las políticas de desarrollo. Un análisis crítico", en Espiral, septiembre-diciembre, vol. 9, núm. 25, Universidad 
de Guadalajara, Guadalajara, México, pp. 69 105. Versión electrónica que aparece en la Red de Revistas Científicas de América Latina y el Caribe. Ciencias Sociales y Humanidades, en su portal http://redalyc.uaemex.mx.

García Aguirre Feliciano (2003), "El Plan Puebla Panamá: previsibles consecuencias", en Theomai, verano, número 099, Universidad Nacional de Quilmes, Quilmes, Argentina, pp. 1-13. Versión electrónica que aparece en la Red de Revistas Científicas de América Latina y el Caribe. Ciencias Sociales y Humanidades, en su portal http://redalyc. uaemex.mx.

Levy, Santiago, Dávila, Enrique y Kessel, Georgina (2000), "El sur también existe: un ensayo sobre el desarrollo regional de México", en México, Secretaría de Hacienda y Crédito Público: Subsecretaría de Egresos, julio de 2000.

Ornelas Delgado, Jaime (2002), “El Plan Puebla Panamá y la globalización neoliberal”, en Aportes, septiembrediciembre, año/vol. VII, número 021, Benemérita Universidad Autónoma de Puebla, Puebla, México, pp. 137-155. Versión electrónica que aparece en la Red de Revistas Científicas de América Latina y el Caribe. Ciencias Sociales y Humanidades, en su portal http:// redalyc.uaemex.mx.

\section{Páginas de Internet}

Beas Torres, Carlos (2000), "Megaproyecto del Istmo. La invasión global”, en http://www.mesoamericaresiste. org/documentos/LibroMega.htm [10 de diciembre de 2003].

Bonilla Sánchez, Arturo (2000), "El macroproyecto en el Istmo de Tehuantepec y privatizaciones; atentados contra la soberanía nacional", en http:// www.mesoamericaresiste.org/document/arti2. html, [10 de diciembre de 2003].

García A., Miguel Ángel (2000), "El Megaproyecto del Istmo de Tehuantepec: Globalización y deterioro ambiental", en http://www.mesoamericaresiste. org/document/artil.html, $[10$ de diciembre de 2003].

Proyecto de Integración y Desarrollo de Mesoamérica (2009), "Presentación enero de 2009", en el portal oficial www.proyectomesoamerica.org, [2 de septiembre de 2009].

Proyecto de Integración y Desarrollo de Mesoamérica (2009), "Presentación marzo de 2009", en el portal oficial www.proyectomesoamerica.org, [2 de septiembre de 2009].

Proyecto de Integración y Desarrollo de Mesoamérica (2008), "El PPP: avances, retos y perspectivas. Evolución del Plan Puebla Panamá hacia un Proyecto de Integración y Desarrollo de Mesoamérica: 'Proyecto Mesoamérica'. Informe ejecutivo. Comisión Ejecutiva del Proyecto Mesoamérica. Villahermosa, Tabasco, México, 27 y 28 de junio de 2008", en el portal oficial www. proyectomesoamerica.org, [2 de septiembre de 2009]. Proyecto de Integración y Desarrollo de Mesoamérica (2009), "Informe Ejecutivo 2008-2009. Comisión Ejecutiva del Proyecto Mesoamérica. Guanacaste, Costa Rica, 29 de julio de 2009", en el portal oficial www. proyectomesoamerica.org, [2 de septiembre de 2009].

Proyecto Mesoamérica (2009), “Antecedentes”, en el portal oficial http://portal2.sre.gob.mx/mesoamerica, [2 de septiembre de 2009].

Proyecto Mesoamérica (2007), "Cumbre de Campeche (2007)", en el portal oficial http://portal2.sre.gob.mx/ mesoamerica, [2 de septiembre de 2009].

Proyecto Mesoamérica (2009), "Cumbre de Villahermosa (2008)", en el portal oficial http://portal2.sre.gob.mx/mesoamerica [2 de septiembre de 2009].

Proyecto Mesoamérica (2009), "Etapa del Plan PueblaPanamá”, en el portal oficial http://portal2.sre.gob. mx/mesoamerica, [2 de septiembre de 2009].

Proyecto Mesoamérica (2009), "Funciones y estructura del Proyecto Mesoamérica”, en el portal oficial http:// 
portal2.sre.gob.mx/mesoamerica [2 de septiembre de 2009].

Proyecto Mesoamérica (2009), "Preguntas frecuentes", en el portal oficial http://portal2.sre.gob.mx/mesoamérica [2 de septiembre de 2009].

Rajchenberg, Enrique y Héau-Lambert, Catherine (2002), "En la antesala del Plan Puebla-Panamá: Tehuantepec en el siglo XIX", en http://www.ezln. org/revistachiapas/Nol4/chl4rajchenberg-heau.html [2 de septiembre de 2009]. x Cumbre de Jefes de Estado y de Gobierno del Mecanismo de Diálogo y Concertación de Tuxtla. Declaración de Villahermosa (2009), en el portal oficial www. proyectomesoamerica.org, [2 de septiembre de 2009].

XI Cumbre de Jefes de Estado y de Gobierno del Mecanismo de Diálogo y Concertación de Tuxtla. Guanacaste, Costa Rica. 27, 28 y 29 de julio (2009). Declaración de Guanacaste, en el portal oficial www.proyectomesoamerica.org, [2 de septiembre de 2009]. 